\section{MEDICAL EDUCATION AND THE UNIVERSITIES.}

A Memorandum on Medical Education subitted to T'He Royal Commission on University

Education in London.

By FRIEDRICH VON MÜLLER, M.D., LL.D., PROFESSOR OF CLINICAL MEDICINE AT THE TNIVERSITY OF MUNich.

IT is impossible for me to attempt to give you advice with regard to the reform of medical education in London. I really know too little about the English medical schools of to-day, because it is many years since I visited the London hospitals, and during the last twenty years not only the science of medicine but also the English medical schools have made important progress.

The difference between English and German medical clucation is founded on their historical development, and we understand it only by the study of their history.

Historical development is one of the most important factors in crilture, and we never realize its importance so clcarly as in the case of those younger countries where no historical development exists. But the burden of a noble past may sometimes become a hindrance to salutary reform, which appears indeed like sacrilege.

In England the instruction of the apprentices of medicine was always entrusted to the profession and the hospitals. The training was truly professional and practical, as in the case of the trades. This system gave to English medicine its strength, because it developed in the young beginner the faculty of strict observation, which is one of the great prerogatives of English medicine.

In Germany since the Middle Ages medicine has always formed part of the university curriculum. Instruction in medicine was in former times almost entircly theoretical and historical, founded on the Latin classical literature, and in closest connexion with philosophy and even with theology. The darkest periods of decay in German medicine were those in which philosophical speculation and theological mysticism obtained a preponderant in fluence over medical problems.

But, on the other hand, this connexion between medical education and the university has proved beneficial, because it admitted of a broader basis, a closer community with other sciences, and because it gave, and still gives, to the physician his social and intellectual position among the learned men of the nation. This is the reason why we shall never give up university education for the medical practitioner.

The student who wishes to enter the medical faculty must have come through the same schools, and passed the same examinations in Latin and Greek, or in English, French, and mathematics, as the students who intend to become lawyers, philologists, clergymen, or natural scientists. The preliminary conditions of admission to the university are the same for all students.

The German medical student lives dming his whole university carcer among the other students of the university. He has his friends, his sports, his duels among them, and therefore he is for the rest of his life connected with the representatives of the other scientific vocations.

University education in Germany is founded upon the principle of absolute freedom of learning, and this is just as true of the medical faculty as of any other. The student is not bound to follow a prescribed course of study. He is allowed to go his own way and to select his teachers and lectures himself, and nobody cares whether he is present at every lecture or whether he is idle. Only a few lectures, laboratory work and clinics are obligatory. Too much tutelage and prescription are of no good in the education of the adult.

This system of absolute liberty is of great importance for the teacher, because he is always sure that his pupils come spontaneously to his lectures and not by compulsion.

The student is not bound to one university alone, he is free to wander to others, and the miajority pursue the course of their studies in more than one iniversity like the wandering students of past centuries. We approve of this becanse it widens the intellectual horizon and induces a mental attitude of educated criticism.

This system of absolute liberty has its dangers. Many weak and unprincipled characters are rtiined by the total absence of control, and neglect their studies. But the strong are allowed to develop their faculties in accordance with their own ideals.

During his first and second year the medical student attends lectures and does laboratory work in physics, chemistry, botany, and zoology in the philosophical faculty, and he has the opportunity of widening his views by listening to lectures on philosophical or historical subjects. His teachers and laboratories are the same as for the students of the natural sciences, and this is right, because there is no such thing as special medical physics or chemistry, but the physician requires a broad knowledge of the general sciences of physics and chenistry.

Another difference between the Fnglish and German institutions arises from the very different conceptions which obtain of the obligations of the State Government.

In England and America social progress is to a great extent dependent on private initiative, and the creative impulse of independent and devoted individuals has always led to the greatest benefits for the community.

In Germany and France the citizen is more accustomed to be guided by the Government, and he commits the important questions of the general welfare to the care of the State.

Our view is that it is the interest of the community to obtain an adequate supply of the best medical attendance. We believe that neither the profession nor the hospitals have as great an interest as the community in the education of the young physician. Therefore it is the duty of the State Government, as the representative of the community, to care for the best possible education of the young medical generation and to provide the money for this purpose. We think this conclusion is logical. If so, the State Government has also the duty of selecting the best teachers and of paying them adequately, so that they may be able to devote their whole time, or at least the greater part of it, to fulfilling their obligations as teachers. This principle applies to the clinical teacher as well as to others, for he is one of the most important in the medical faculty. It is not proper that the clinical professor should be burdened with great obligations as a teacher and at the same time compelled to support himself by private practice.

The salary of university professors in Germany is not bad. It amounts for an ordinary professorship to $£ 200$ to $£ 500$ a year, and permits him to maintain a gocd social position.

Besides the ordinary professors, who hold the principal chairs, there are extraordinary professors and junior teachers, who instruct in the auxiliary or less important subjects of medicine. They receive a salary of $£ 100$ to $£ 250$ a year. The number of ordinary professors in every medical faculty is from 10 to 17 . The number of the adjunct professors varies from 6 to 32 .

But this salary paid by the State does not form the whole income of the university professor. The student pays for every lecture or clinic a certain small sum, on the average 10s. to $£ 2$ for the half-year. A portion of this money is taken by the university; but the greater part goes to the professor, and this Collegiengeld forms a more or less considerable part of his income. This system is of some importance, because the teacher's income depends to a great extent on the number of his students. He has, therefore, an interest in making his lectures as attractive as possible, and in spending his time and energy for this purpose.

Moreover, the State provides and maintains the buildings necessary for medical instruction and the equipment of the laboratories. Every university has its large buildings for anatomy, physiology, and biological chemistry, for pathology, pharmacology, and hygiene. To keep pace with the cxtension of science the number and size of these institutions are constantly growing, and demand enormous expenditure.

I talic for example Bavaria. It has 7,000,000 inlıabitants, approximately the same as Greater London. Bavaria has three universities, and therefore three fully equipped medical faculties.

The sum paid by the State for the salaries of the teachers of medicine in these three universities amounts to $\mathfrak{E} 19,700$, or from $£ 5,000$ to $£ 8,000$ a year for each university. This does not include the salaries of the large number of assistants or the pensions of retired professor's and the widlows of dcceased professors. 
Within the last ten years the University of Munich has got a new building for anatomy at a cost of $£ 125,000$, a new psychiatric clinic costing $\mathfrak{£} 100,000$, a great ophthalmological clinic costing $£ 125,000$, and a new building for. outpatients costing $£ 125,000$. The maintenance of these university institutions and laboratories of course involves a large annual expenditure. The sum paid for the maintenance of the different institutions for medical education, including the clinics in the three Bavarian universities, amounts to $£ 80,000$. The State Government of Bavaria was kind enough to give me these statistics and to give me permission to bring them before this Royal Commission.

The other confederate States of Germany have similar expenses for their medical faculties: Baden has two universities; Würtemberg, Saxony, Mecklenburg, Thuringia, Alsace have each one. Prussia with its ten universities is subjected, of course, to much greater expense than the States of Germany.

At my request the State Government of Prussia has given me particulars of its expenditure on medical education. I feel greatly obliged indeed to the Prussian Ministry for Public Instruction for this information. We learn from this evidence that Prussia spends on its ten universities for salaries for the medical teachers $£ 116,000$, for the maintenance of the medical institutes and clinics $£ 413,200$ - a total of $£ 530,000$ a year. The number of students of medicine at the ten universities is 5,365. Therefore the Prussian. State contributes towards the education of every student of medicine $\$ 95$ a year.

For the building and fitting-out of new medical institutes and clinics Prussia has expended within the last twentyfive years $£ 2,573,400$, or $£ 102,936$ a year.

Every medical faculty of the twenty German universities has a medical, surgical and obstetrical, psychiatric, and ophthalmological clinic. Most of them have a clinic for dermatology and venereal diseases, for pediatry and otology. Some of the greater ones have also clinics for orthopaedics and throat diseases. Berlin and Munich have two parallel clinics, because one alone would not be sufficient for the great number of students of medicine, which in Munich exceeds 2,000.

In addition to the clinics, there are large out-patient departments in special buildings, and with their own staf of physicians and teachers. The new building for outpatients in Munich erected in recent years contains outpatient departments for internal medicine, surgery, pediatrics, gynaecology, otiatrics, throat diseases, dermatology, and orthopaedics. The capital cost of the buildings and equipment exceeded $£ 125,000$, and its yearly maintenauce costs $£ 10,000$.

You see that Germany not only speuds great sums for the army and navy, I say for the prevention of war, but also much money for medical purposes, and therefore for the prevention of disease.

The connexion between the clinical hospitals and the medical faculties is not of the same type in all universities.

In some universities, such as Leipzig and Munich, the hospitals belong to the city, they are municipal, and by agreement the municipality opens its hospital entirely or partly to medical instruction. The clinical teachers are the physicians-in-chief of the city hospital, and are appointed by the city government and the university together. In Berlin the War Uffice of the lingdom is in possession of the Charité Hospital. The Charité was built by King Frederic Wilhelm I for the instruction of the surgeons of the army. In 1810 the University of Berlin was founded, and the general clinical teaching was transforred to the Charité. In some older universities the country hospitals came into connexion with the university.

But with the expansion of clinical teaching it became evident that some of the older hospitals were not sufficient for the new requirements, and some municipal governments and other hospital administrations were at one time unwilling to offer increasing facilities to the medical faculties. Some of the municipalities were shortsighted enough to refuse altogether to admit students to their wards, because they feared that the patients would suffer at their inexperienced hands (and this not entirely without reason, because the patients really do suffer from too much examination).
For this reason the university, that is the State, found itself more and more obliged to build its own university hospitals. Most of them have been built in the last twenty years, and are constructed on modern principles.

It is necessary that the clinical hospitals should contain a sufficient number of beds, that they may be able to admit a sufficient selection of interesting and instructive cases, and also to cover the whole field of medicine. I think a medical clinic should have at least 120 to 150 beds. The Munich clinical hospitals have more than 1,200 beds, the Leipzig clinical hospitals 1,360 beds, the Charité at Berlin more than 1,800 beds.

But who shall pay for all these patients? The university again? No.

The State pays only a comparatively small part for the admission of some specially interesting cases. The great majority of the cases are paid for by the insurance fund and by the Poor Law administration.

It will be well known to the Royal Commission that in Germany every workman and workwoman and all domestic servants are compulsorily insured against disease. In case of illness or accident they have the right to free treatment and admission to a hospital, and the insurance fund is obliged to pay to the hospital for every patient admitter a certain sum, averaging $3 \mathrm{~s}$. a day. This sum is almost sufficient to cover the expenses of the hospital, so that they are able to maintain their budget by the contributions from the incurance fund.

In reply to our inquiry, Professor Muiller has been good enough to send us the following additional information: The clinical physicians and surgeons, who treat in the hospitals patients sent in by the insurance fund or by the Poor Law authority do not receive any payment from the fund or from the Poor Law. The hospital physicians are paid by the municipality or by the State Government. And it is the duty of the hospital physicians and surgeons to treat all patients of the hospital, whether they be sent in by insurance or Poor Law or come in of their own will. The difference between the English and German system is that hospital physicians in Germany receive salaries and the English do their work for charity. The money paid by the insurance or Poor Law for every patient and every day forms the greatest part of the total income of the hospital budget. From this budget all expenses of the hospital are paid, including the salaries of the head physicians and assistants, but these salaries of the medical staff are fixed, and not dependent on the number of patients.]

The duty of caring for the destitute poor falls on the Poor Law commission of the parish, or on the municipality, and so they, too, are paid for. 'The hospital patients therefore are not admitted by charity, and our hospital work is therefore not so much charity work as in England. Most of our patients have a right to be admitted, and they cannot be discharged till they are cured or till their time is over. This is the reason why our patients are not all willing to be examined by the students or to be made the subjects of demonstration in the theatre. The sum paid for insurance of the working classes amounts in Germany to nearly $\$ 18.000,000$ a year. Should we not characterize it as expenses paid for tho prevention of social war?

England has now initiated new social laws for the insurance of the working classes. I am sure it will soon be compelled to erect great new hospitals for those insured patients who cannot afford proper treatment at home. And it may be useful to bring those hospitals into connexion with the university teaching of medicine.

I now wish to draw your attention to some points of the existing medical education in Germany.

The student enters the university at the age of 18 or 19 years. He first begins, as I told you, with physics, chemistry, biology, and other natural sciences in the class-rooms and laboratories oi the philosophical faculty. At the same time he receives instruction in anatomy, and dissects in the anatomical institute of the medical faculty.

In the second year and the first half of the third year he attends lectures in normal histology and embryology. The history of ontogenetic and phylogenetic development is proving year by year more important for the conception of pathological processes, for the anatomy of the brain, and other problems. It is therefore absolutely necessary to teach this science to the medical students. 
Lectures in physiology and laboratory work in experimental biology and biological chemistry complete the course of the preliminary studies.

After he has passed his first examiuation in these subjects the student, in the second half of his third year. enters upon his professional studies through the door of general pathology and pathological anatomy in the dissecting room and microscopic laboratories of the pathological institute. At the same time he attends lectures on pharmacology, which is developing more and more into experimental pathology. In the hospital wards he takes practical instruction in the physical examination of patients, in propaedeutics of surgery and midwifery, and in clinical chemistry and microscopy.

He is then prepared to enter the clinic. Our method of clinical teaching differs in one important point from that in England. In English medical schools the young student is immediately brought in contact with the patient. Under strict control of the house-physician he has to write the record of his patient and to follow the course of his case every day. From practical experience of a relatively sinall number of patients he learns how to examine and to treat them.

In Germany, and especially in the larger universities, the clinical teacher shows to all his students in the theatre every day one or two selected cases which are specially adapted to illustrate the conception of the disease. The patient is examined before the whole class, the teacher explains the symptoms and discusses the general pathological questions which are connected with the case. So the student sees a great variety of diseases, and we try to give him a complete picture of the single case. Only when he has first acquired some general knowledge do we bring him into closer contact with the patient under control of the assistants. For every single patient shows such complicated possibilities that the beginner cannot understand the whole significance of the case until he has acquired a certain fund of knowledge.

When the student in his fourth year has finished his hospital work in internal medicine, surgery, and midwifery, he goes to the out-patient department. Here he learns to deal with all the difficulties of his future professional life. The ont-patient department should be for the advanced student the dirert introduction to his practical work.

In England the student begins with the out-patient department and then enters the clinical wards. In Germany we go the reverse way. We believe it is more difficult and requires greater experience to deal with out patients and find out quickly the essential points than to work under direction in the wards of a hospital, where the cases are far better prepared and more thoroughly examined by the assistant and the head physician. During his last year the student has to attend the ophthalmological, psychiatrical, pediatrical, and dorma. tological clinics, otiatrics, throat diseases, and other specialities. Lectures and laboratory work in bacteriology and hygiene and dissections of pathological cases form the conclusion.

After the end of his fifth year the student is allowed to go up for his final examination. But many of the students spend another half-year before they do so. This examination gives the licence to practise.

While the universities are under the management of the particular States, the examination is conducted under the control of the Empire, and the passing of it confers the rights to practise in all parts of the Empire.

The State Government controls the examination and appoints the examiners. It can appoint medical practitioners to be examiners, but as a rule the teachers-that is, the university professors-examine, and this rule bas proved satisfactory. We do not find any disadvantages in this system. For the teacher it has the great advantage that he is able to find out whether his instruction has been successful, and whether his lectures were well understood by his pupils. For the student it is agreeable that he is sure not to find great discrepancies between his studies and his examinations. It is not at all obligatory that the student should pass this examination at the same university at which he has studied.

After the State examination the successful candidate is not immediately permitted to enter upon his practice. He is compelled to devote a ycar entirely to practical hospital work under control of the hospital physicians. For this purpose not only the university hospitals, but all the hospitals of Germany, are open, and an average of 1,200 young physicians are distributed among a large number of hospitals.

In this way the more theoretical introduction of our German medical instruction is compensated by the prastical work of the final year. Some of the larger city hospitals in Frankfort, Cologne, Diisseldorf, and Hamburg have established schools for post-graduates, which have been successful.

Within the last ten years the curriculum of the medical student has been extended by one half-year of university instruction and by the practical year, so that the student comes to carn his living one a half years later than beforc. One could believe that this extension would keep back a great number of young men from the medical career and would have diminished the number of medical students. Just the reverse took place. The number of medical students increased considerably. A study of so great interest, like medicine, which shows such splendid scientific progress, will always attract the spirits of enthusiastic youth.

Examination is a very important thing, because it is a necessary control not only for the students but also for the teachers. But we should not forget that the examinations are not the principal object. They may be so in China. The range and scope of study is far more important, and it is not the province of the university to prepare for examinations but for the future life and vocation. Reform must begin with the instruction and not with the examinations.

It is easy to conceive that reform often meets with more resistance from the teachers than from the students, and that it takes a much longer time and is more difficult to reform a corporation of teachers than to accustom the young generation to a reformed system.

We must distinguish sharply between the State examinaticn, which gives the licence to practise, and the academical degree. The degree of M.D. can be conferred by the medical faculty in all German universities upon nearly the same conditions. While the State examination is especially practical and has to furnish eviderce that the candidate is mature for practice, the degree of M.D. ought to indicate that the man has contributed his part to scientific work. The degree should be a scientific qualification. It is not a more rigorous second examination superimposed on the State examination which gives the degree, but the candidate must present a piece of scientific work: some experimental investigations or some clinical observations with consideration of the pertinent literature. This paper or dissertation must be approved by the faculty and must be printed.

We have now got some idea of the course of medical study. Finally, I wish to say a few words about the teachers. Since the teachers of anatomy, biological chemistry, pathology, pharmacology, hygiene, and so on are university professors, it is clear that their selection follows the same lines as in the case of the university professors in general. This means that in the case of a vacancy the best man available should be chosen. Only those who are actively engaged in scientific research and play their part in the promotion of science are capable of being university teachers.

Since the clinical hospitals are well-established institutions of the university, and because the clinical teachers are fully acknowledged university professors, they must be selected from the scientists and not from among the successful practitioners. Clinical medicine is as truly scientific as physiology, but it is not so much a science in itself, it is more an application of all available sciences to the relief of suffering humanity and the prevention of disease. The clinical professors, therefore, should have a wide scientific foundation apart from practical medicinc, it may be in pathology (anatomical or experimental) or in physiology (physical or chemical); the clinical teacher must be fit not only to conduct the work of his wards but also the work of his laboratories.

But, above all, he must be a good physician, because he has to instruct the young generation in practical medicine. If he should not be thoroughly acquainted with the practice of medicinc there would soon arise discrepancy between the university teachers and profes sional medicine-such a disagreement as we find between 
scientific jurisprudence and the practice of law, and which we all deplore. 'For' such discrepancies the student has a keen sense.

The professor of clinical modicine has to consider his professorial work as his principal duty, as every other university professor does. He has to derote the main portion of his day to his hospital wards, to his teaching, and to his laboratory.

It is not a recommendation for a clinical professor if he has a large private practice. On the contrary, it is a pity, and it is not fair if he wastes too much of his time in consultations instead of devoting it to his university work. The limit of his private consulting practice must be left to his own conscientiousuess.

Should he not be peimitted to have private practice at all? I think this goes too far. The clinical teacher should be in constant touch not only with the progress of science, but also with general professional life, and the practitioners, too. If he should be confined entirely to his laboratory and hospital he would be liable to malie mistakes and come to wrong conclusions.

The clinical professor must have his staff of well educated assistants. The conduct of a modern medical clinic needs, to-day, at least one assistant thoroughly experienced in biological chemistry, one in the experimental physical methods of biology, including the investigation of the heart and the $x$-ray work, and one in bacteriology and serology, so that he may be able to work out the Wassermann test and difficult serological diagnoses. It is an excellent plan for one assistant to have charge of all questions of the blood and pathological histological examinations, and one of the diseases of the nervous system. The assistants should not be changed every year, because it takes a long time to train and develop an assistant thoroughly, and because it is obvious that an older and highly accomplished assistant is of much greater value to the clinic than a junior man.

The future clinical directors will be selected from the number of the old and thoroughly trained clinical assistants. The clinical assistant knows that his future caree as a professor of medicine depends mainly on his scientific work, and this gives him a great compulsion to devote himself to scientific investigation. But a school of assistants of a high degree of excellence can only flourish under the conduct of a thoroughly scientific clinical director.

If the conception of the position of the clinical teacher I have placed before you is accepted, it is obvious that he must be in charge of his wards and laboratories throughout the whole year. Under this condition alone can he conduct the work of his wards and control his assistants and his nurses with a strong hand. If the chief physician changes place every three months, or if there are too many of them in one hospital, so that every one has only a small number of beds, then not the clinical professor but the housephysician or the head nurse will be the real governor, to the detriment of the hospital.

The selection of a university professor for a vacant chair should not be restricted to the junior members of the same sshool. And this rule applies not only to the selection of the theoretical professors, but also and especially to the clinical positions. 'The selection must be made from a wicle field, from all universities, not only of the same country, but of the same language.

Inbreeding is the worst thing in the development of the race, and a law which is so general in Nature, and whose bad effects are so carefully avoided in all realms of Nature, cannot be without importance for the regeneration of a university. Fresh blood and competition with the other best centres is the chief consideration for the welfare of the universities and hospitals.

Is it really necessary to incur such great expenses as we have spoken of in every medical school? Would it not be possible to conduct the school for the common practitioner in the old well-established manner? No. The general medical practitioner has always and everywhere to deal with the highest good, with the health of his fellow creatures, and he must become more and more, even in the remotest village, the promoter of public health, and therefore he must be an educated man. In his responsible vocation he must have some ideal which elevates him above the daily sorrows and disappointments of life. And he will find his refuge in his science. Only a good scientific education will enable him to follow the progress of medicino with critical understanding. Without a good scientific training he would sink into mere routine.

In all questions which are connected with educational problems we must be arvare that we have to care for the future, for the next generation. A plan of reform which is only intended to meet the wants of the present day is wrong from the beginning. All our plans for reform must be broad enough to allow further expansion and accommodation to the necessities of adrancement in science.

\section{SCIENCE NOTES.}

Is the course of his presidential address from the chair of the Roentgen Society at the November meeting, Mr. A. A. Campbell Swinton, M.I.E.E., said that while the results of modern discovery had failed to weaken belief in the great principle of the conservation of energy, as definci in the first law of thermo-dynamics, the second law stood upon a different footing. As stated by Lord Kelvin, this second law implied that it was impossible by means of inanimate material agency to derive mechanical effect from any portion of matter by cooling it below the temperature of the coldest of the surrounding objects. Lately, in London, as a result of Bergson's teaching, there had been an outbreak of metaphysical discussion, in the course of which the question had been raised whether living oryanisms were subject to the laws of thermodynamics or not. The general answer, as to the first law, was in the affirmative, but as to the second there was a wide difference of opinion, and many now accepted the probability that certain animate bodies, acting very much like Maxwell's celebrated theoretical "demons," were ablo by manipulating the molecules of matter to extract the energy they required from the general stock of heat. Thus they evaded the provision of the second law, which stated that by the use of no machine could we get mechanical effect from the general stock. The interest of the question would be especially evident to those who had studied tho so-called Brownian movements, which could be perceived by ultra-microscopic methods in finely-divided solid matter, such as particles of colloidal gold suspended in a liquid, or. of tobacco smoke in a gas. These movements were now believed to be due to the actual jostling of the minute particles by the moving molecules themselves, and gave the most wonderful notion of the state of ceaseless agitation that existed among the molecules of all substances at any temperature above that of absolute zero, and the vast amount of energy that was stored in these perpetual movements. Without pronouncing one way or the other, Mr. Swirton drew attention to the stupendous consequences that would follow if such a view could be established. It would give the world the equivalent of the burning lamp of the story-books, which consumed no oil, or the perpetual fire of the burning bush which required no fuel. It would only be necessary to cultivate the right kind of organisms in sufficient masses to produce the perpetual motion dreamed of by the mediaeval philosophers. Professor Silvanus Thompson, in moving a vote of thanks, said that Lord Kelvin was well aware that it was not possible to account for the operations that went on in the human machine on the supposition that man was a thermo-dynamic engine. Man's "boiler temperature" was not a boiling point, his "condenser temperature" was not a freezing point, and these two temperatures were so close together that the ratio of the difference between them to the absolute temperature of the supply, which would give the available energy in the case of the steam engine, did not represent in the case of the man one-thousandth part of the "fuel" stoked in, and was thus quite out of the question. It was therefore necessary to suppose that there was some other and unknown law of thermo-dynamics. pertaining to the vital operations of physiology, enabling the animal to obtain light and heat by concentrating it from the diffused energy of the universe. This possibility was not absent from Lord Kelvin's mind, as was shown by his opposition to the theory of Rutherford and Soddy which accounted for radio-activity by the disintegration of the atom, and his insistence upon the view that the reason why a radio active body remained hotter than its surroundings was because it was able to concentrate the diffuse energies of the general stock. 